\title{
Three new species of the feather mite genus Pteroherpus Gaud, 1981 (Astigmata, Pteronyssidae) from the bulbuls (Passeriformes, Pycnonotidae) in Africa
}

\author{
Sergey V. Mironov ${ }^{*}$ and Georges Wauthy² \\ 1Zoological Institute, Russian Academy of Sciences, Saint Petersburg, 199034, Russia; ${ }^{2}$ Institut Royal des Sciences Naturelles \\ de Belgique, rue Vautier 29, B-1000, Bruxelles, Belgique
}

\begin{abstract}
Three new species of the feather mite genus Pteroherpus Gaud, 1981 are described from the bulbuls (Passeriformes, Pycnonotidae) in Africa: Pteroherpus nicator sp. nov. from Nicator gularis Hartlaub et Finsch, 1870, P. pyrrhuri sp. nov. from Pyrrhurus scandens (Swainson, 1837), and P. trinoton sp. nov. from Phyllastrephus terrestris Swainson, 1837.
\end{abstract}

\section{Key words}

Pteronyssidae, Pteroherpus, taxonomy, Pycnonotidae, Africa

\section{Introduction}

The feather mite family Pteronyssidae (Astigmata, Analgoidea) currently includes approximately 130 species in 22 genera (Faccini and Atyeo 1981; Gaud and Atyeo 1996; Mironov 2001, 2003). Mites of this family are mainly distributed on hosts from the orders Passeriformes and Piciformes with only a few species recorded from the Coraciiformes. Within the plumage of their hosts, pteronyssids inhabit the ventral surfaces of flight feathers and the large upper covert feathers of wings.

Among seven pteronyssid genera restricted to passerines, the genus Pteroherpus Gaud, 1981 is a relatively species-rich taxon, which prior to this work included 14 species (Gaud and Mouchet 1959; Faccini and Atyeo 1981; Mironov and Kopij 2000; Mironov 1992, 2001). Mites of this genus are medium sized for pteronyssids (adults are about 300-550 $\mu \mathrm{m}$ ). They are known from hosts of six families belonging to "higher" passerines (Oscines) from the Old World; almost all species (11) are associated with hosts of the superfamily Sylvioidea (Old World warblers and allies).

The genus Pteroherpus was established in the course of a generic revision of pteronyssid mites (Gaud in Faccini and Atyeo 1981). The 12 species initially included in this genus were removed from the complex genus Pteronyssus Robin, 1877, which previously encompassed all pteronyssid species with epimerites I fused as a Y. The main diagnostic feature differing Pteroherpus from other pteronyssid genera was the bifurcate dorsal palpal seta $d p 2$, a unique feature within this family (Fig. 1A). In the course of further taxonomic studies, seven more species were described as belonging to this genus (Mironov 1992, Mironov and Kopij 2000); however, five of these were subsequently removed to three separate genera, Dicrurobius Mironov, 2001 (1 species), Micropteroherpus Mironov, 2001 (3 species), and Vanginyssus Mironov, 2001 (1 species) (Mironov 2001). Thus, within the family Pteronyssidae, Pteroherpus and these three genera constitute the Pteroherpus generic group characterized by having bifurcate setae $d p 2$. In the context of this group, the genus Pteroherpus is characterized by the following combination of diagnostic features: In males, tarsus III is bidentate, supranal concavity does not extend to setae $e l$, opisthosomal lobes are short, rounded, and commonly close to each other (Fig. 1A-E); in females, the hysteronotal shield is represented by 4-9 paired and unpaired sclerites, among which the pygidial sclerite is always paired and the opisthosomal sclerites are entire or split into inner and lateral fragments, hysteronotal gland openings $g l$ are situated on opisthosomal sclerites (Fig. 4A, C and D).

In the present paper, we describe three new species of the genus Pteroherpus found on the bulbuls (Passeriformes, Pycnonotidae) in the course of our study of feather mites associated with African passerines (Mironov and Wauthy 2005a-c). 

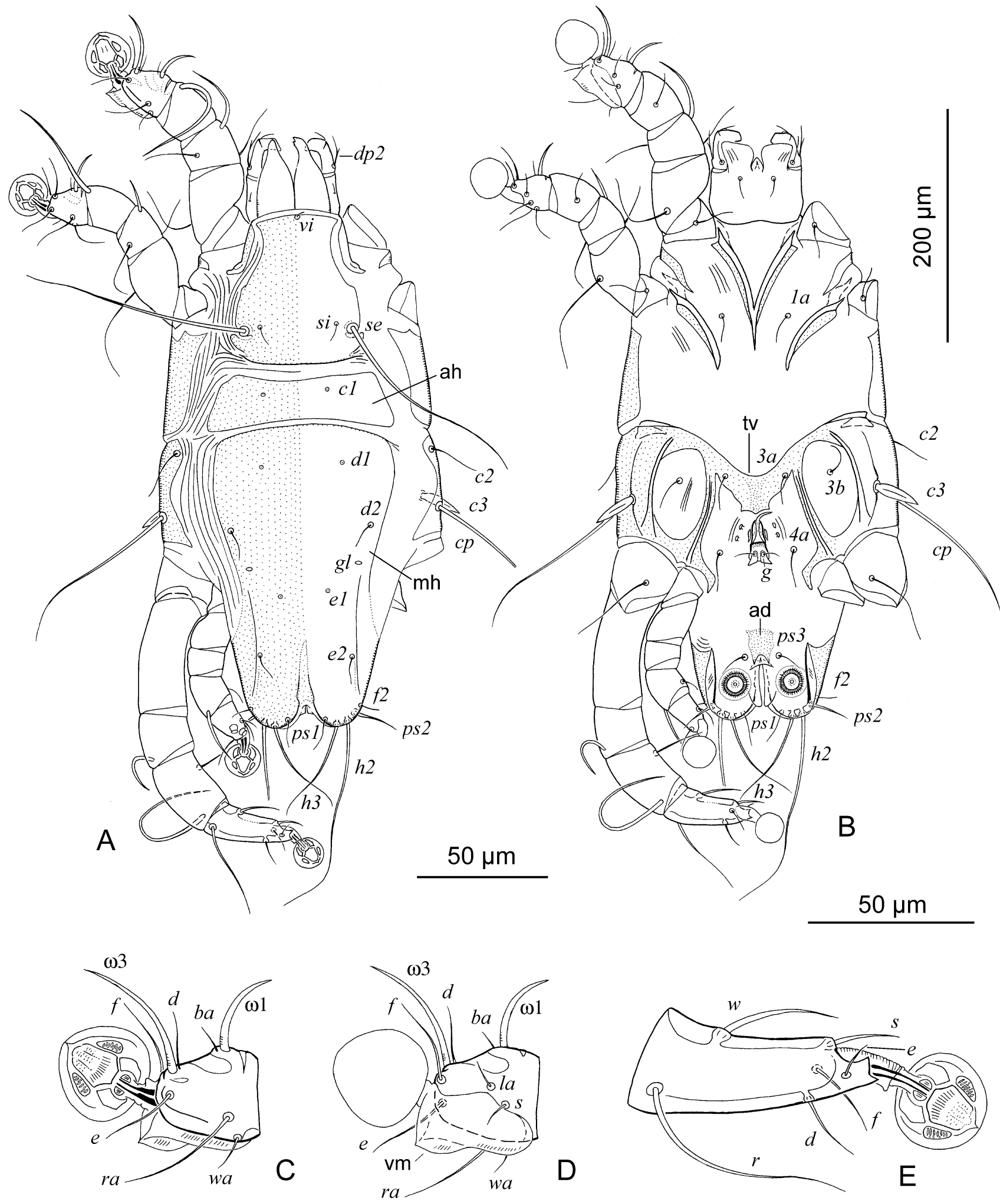

Fig. 1. Pteroherpus trinoton sp. nov., male: A - dorsal view, B - ventral view, C - tarsus I, dorsal view, D - tarsus I, ventral view, E - tarsus III, dorsal view; ad - adanal shield, ah - anterior fragment of hysteronotal shield, mh - main body of hysteronotal shield, tv - transventral sclerite, vm - ventral membrane of tarsus I 


\section{Materials and methods}

The main part of the material used in the present study was borrowed in a loan from the Musée Royal de l'Afrique Centrale (Tervuren, Belgium) and the University of Georgia (Athens, U.S.A.).

The general morphological terms and nomenclature of leg and idiosomal chaetotaxy follow Gaud and Atyeo (1996). Descriptions of new species are given in the standard formats used for this genus (Mironov 1992, 2001). All measurements in the descriptions are in micrometers $(\mu \mathrm{m})$. A full set of standard measurements is given only for the holotype (male) and one paratype (female); the range of idiosomal size (length, width) is displayed for other paratype specimens of the type series. The standard measurements implying the distance between different pairs of setae represent the shortest distance between the transverse levels formed by setae of respective pairs. Scientific names of birds follow Dickinson (2003).

Specimen depositories and reference accession numbers are cited using the following abbreviations: MRAC - Musée Royal de l'Afrique Centrale, Tervuren, Belgium; MZUM Museum of Zoology, University of Michigan, Ann Arbour, U.S.A.; NU - Nebraska University, Lincoln, U.S.A.; ZISP Zoological Institute, Saint Petersburg, Russia. Where the collection number consists of two parts, the first refers to the collection number of the mite specimens; the second is the collection number of the respective host specimen.

\section{Results}

Pteronyssidae Oudemans, 1941

Pteroherpus Gaud, 1981

\section{Pteroherpus trinoton sp. nov. (Figs 1A-E and 4A, B)}

Male (holotype): Idiosoma length $\times$ width $435 \times 240$ (idiosomal size in 1 paratype $425 \times 220$ ). Length of hysterosoma 240 . Prodorsal shield: Posterior angles rounded, lateral margins with small incision posterior to setae se, posterior margin slightly convex, size $132 \times 113$, setae se separated by 90 . Setae $c 2$ hair-like, 40 in length; setae $c 3$ lanceolate, $37 \times 7.5$. Hysteronotal shield consists of the main body of this shield occupying hysterosoma and anterior fragment situated in posterior quarter of propodosoma; main body of hysteronotal shield with slightly convex anterior margin (Fig. 1A), with rounded anterior angles, length along midline 255 , width at anterior margin 154; anterior hysteronotal fragment as low trapezium; total length of hysteronotal shield (including anterior fragment) 295, distance between prodorsal and hysteronotal shields about 10 . Opisthosomal lobes short, rounded; terminal cleft widely U-shaped, 10 long, length of the cleft including supranal concavity 78; margin of lobes without membrane. Setae $f 2$ dorsal. Dorsal measurements: $c 2: d 262$, d2:e2 112, d2:gl 33, gl:el 24-30, e2:h3 56, h2:h2 72, h3:h3
51. Transventral sclerite Y-shaped, 28 along midline, 22 in width in posterior part; tips of epiandrium scarcely expressed; genital arch $35 \times 20$; aedeagus thin, as long as half length of genital arch. Adanal shield as small poorly sclerotized plate of irregular form (Fig. 1B). Diameter of anal discs 16. Ventral measurements: ps2:ps2 84, ps3:ps3 28, ps3:h3 50. Ventral membrane of tarsus I as long as segment. Tarsus III 75 long, with narrow bidentate apex, all setae setiform, seta $w 33$ long, setae $s$ 22, setae $r$ almost as long as the segment (Fig. 1E). Tarsus IV subequal in length to tibia IV; modified seta $d$ in distal half of segment.

Female (paratype): Idiosoma length $\times$ width $530 \times 250$. Length of hysterosoma 350. Prodorsal shield as in the male, $132 \times 128$, setae $s e$ separated by 84 . Setae $c 2$ short hair-like, 30 long; setae $c 3$ lanceolate, $38 \times 8$. Arrangement of hysteronotal shields: Anterior hysteronotal sclerite, central sclerite, pair of lateral opisthosomal sclerites, pair of inner opisthosomal sclerites, and pair of pygidial sclerites (Fig. 4A). Anterior hysteronotal sclerite as large transverse plate encompassing bases of setae $c 1, c 2$. Central sclerite large approximately rectangular in form, $192 \times 122$. Lateral opisthosomal shields generally ovate, longitudinal, with openings $g l$ in anterior part; 68-76 long, 33-36 wide. Inner opisthosomal sclerites ovate, convergent to midline by anterior ends, 80-85 long, 43-45 wide. Setae $d 1, d 2$ on central sclerite, setae $e 1$ on anterior margin of inner opisthosomal sclerites, setae $e 2$ in posterior half of lateral opisthosomal sclerites. Setae ps 1 at level of setae $h 2$. Dorsal measurements: $c 2: d 2136, d 2: e 2$ 120, d2: gl 88, gl:el 5-8, e2:h3 108, h2:h2 88, h3:h3 84. Epigynium with short lateral extensions and slightly divergent posterior ends, $55 \times 100$ (Fig. 4B).

Diagnosis: The new species is close to Pteroherpus doleoplax (Gaud et Mouchet, 1959) by following features: In female, the anterior hysteronotal sclerite present, unpaired, and free from prodorsal shield, opisthosomal sclerites separated from central sclerite; in males, anterior hysteronotal sclerite present, free from prodorsal shield. The male of Pteroherpus trinoton differs by having longer aedeagus, which is as long as half-length of genital arch, supranal concavity extending by the anterior end beyond the level of setae $e 2$, and poorly expressed tips of epiandrium; the female differs by having opisthosomal sclerites completely split into lateral and inner fragments and setae $e l$ situated on anterior margin of the inner fragments of these shields. In the males of $P$. doleoplax, the aedeagus is as long as one quarter of genital arch, supranal concavity is not extended to the level of setae $e 2$, and tips of epiandrium are extended to midlevel of genital apparatus; in the females, opisthosomal sclerites are C-shaped, i.e. not completely split into fragments, and setae $e l$ are situated on striated tegument.

Type material: Male holotype and 1 female paratype (NU 3824) from Phyllastrephus terrestris Swainson, 1837 (Pycnonotidae), South Africa, Cape Province, Storms River, 31.XII.1953, F. Zumpt; 1 male paratype (NU 3611), same data. Holotype and female paratype - MZUM, male paratype - ZISP. 
Etymology: From notum (Latin - shield), to point out three separate median sclerites on dorsum.

\section{Pteroherpus pyrrhuri sp. nov. (Figs 2A-D and 4C)}

Male (holotype): Idiosoma length $\times$ width $380 \times 215$ (idiosomal size in 5 paratypes $365-383 \times 205-230$ ). Length of hys- terosoma 220. Prodorsal shield: Posterior angles rounded, lateral margins with poorly marked incision posterior to setae se, posterior margin straight, size $106 \times 108$, setae se separated by 90. Setae $c 2$ short, hair-like, 30 long; setae $c 3$ lanceolate, 28 $\times 5$. Hysteronotal shield entire (Fig. 2A), anterior end spreading onto posterior part of prodorsum and encompassing setae $c 1$, anterior margin straight, anterior angles widely rounded,
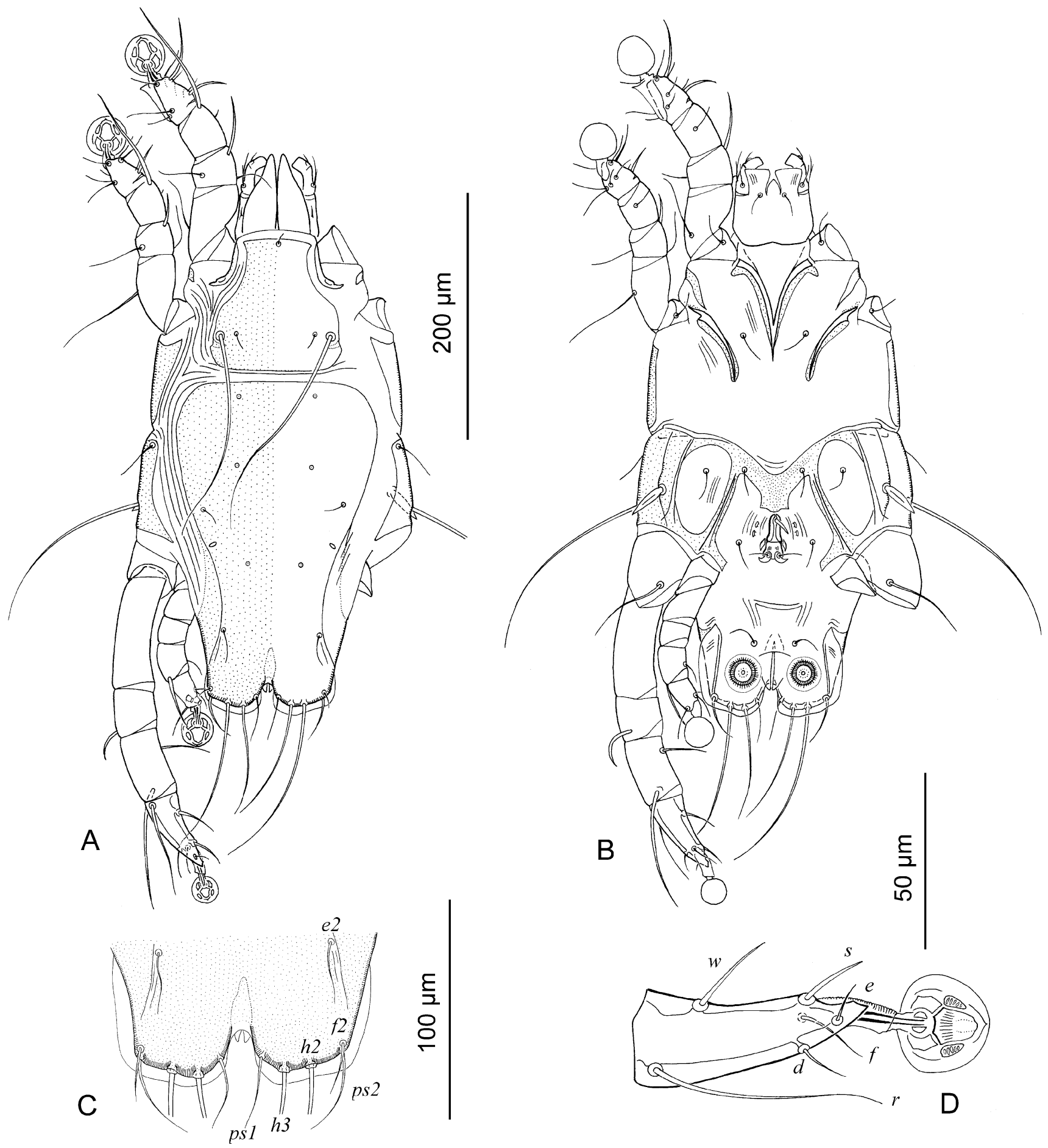

Fig. 2. Pteroherpus pyrrhuri sp. nov., male: A - dorsal view, B - ventral view, C - dorsal view of opisthosoma, D - tarsus III, dorsal view 
length along midline 256, width at anterior margin 160 . Distance between prodorsal and hysteronotal shields 10 . Opisthosomal lobes short, rounded; terminal cleft widely Ushaped, 18 long, length of the cleft including supranal concavity 35 ; margin of lobes and terminal cleft with narrow membrane (Fig. 2C). Setae $f 2$ dorsal. Dorsal measurements: $c 2: d 2$ 52, d2:e2 105, d2:gl 32, gl:e1 18, e2:h3 59, h2:h2 62, $h 3: h 362$. Transventral sclerite Y-shaped, 29 along midline, 20 in width in posterior part; tips of epiandrium scarcely expressed; genital arch $35 \times 18$; aedeagus approximately as long as one third of genital arch. Adanal shield absent. Diameter of anal discs 17. Ventral measurements: ps2:ps2 92, ps3:ps3 32, $p s 3: h 353$. Ventral membrane of tarsus I as long as the segment. Tarsus III 67 long, with obliquely cut apex, its bidentation poorly expressed, all setae setiform, seta $w 25$ long, seta $s$ 18; seta $r$ slightly longer than segment (Fig. 2D). Tarsus IV slightly longer than tibia IV; modified seta $d$ in distal half of segment.

Female (paratype): Idiosoma length $\times$ width $485 \times 230$ (in 6 other paratypes $465-475 \times 210-225)$. Length of hysterosoma 330. Prodorsal shield as in the male, $120 \times 119$, setae $s e$ separated by 94 . Setae $c 2$ short hair-like, 30 long; setae $c 3$ lanceolate, $33 \times 6.5$. Arrangement of hysteronotal shields: Anterior hysteronotal sclerite, central sclerite fused with inner opisthosomal sclerites, pair of lateral opisthosomal sclerites, and pair of pygidial sclerites (Fig. 4C). Anterior hysteronotal sclerite as large transverse plate, encompassing bases of setae $c 1$ and $c 2$. Central sclerite fused with inner opisthosomal sclerites forming large $\lambda$-shaped sclerite covering most of median area of hysterosoma; total length of this sclerite 252, width at anterior margin 102, length of incision in posterior margin 60. Lateral opisthosomal sclerites as longitudinal plates with opening $g l$ in anterior end, 68-70 $\times 24-27$. Setae $d 1, d 2$ and $e 1$ on central sclerite, setae $e 2$ on lateral opisthosomal sclerites. Setae $p s 1$ at level of setae $h 2$. Dorsal measurements: $c 2: d 2$ 128, d2:e2 110, d2:gl 74, gl:el 6-10, e2:h3 104, h2:h2 86, $h 3: h 3$ 84. Epigynium with lateral extensions and slightly divergent posterior ends, $50 \times 82$.

Diagnosis: The new species is close to Pteroherpus doleoplax and to the previous species by the following features: In female, anterior hysteronotal sclerite present, unpaired, and free from prodorsal shield, opisthosomal sclerites separated from central sclerite; in male, hysteronotal shield occupies posterior part of prodorsum and encompasses bases of setae $c 1$. The males of $P$. pyrrhuri differ from these species by having the entire hysteronotal shield extended almost to posterior margin of prodorsal shield (Fig. 2A) and obliquely cut apex of tarsus III (Fig. 2D). The females differ by structure of opisthosomal sclerites: Each sclerite completely split into lateral and inner fragments; the latter fragments are fused to central sclerites (Fig. 4C). In the males of P. doleoplax and P. trinoton, the anterior part of hysteronotal shield is split from the main body of the shield, and apex of tarsus is clearly bidentate; in the females, inner opisthosomal shield or its fragments are separated from the central sclerite.
Type material: Male holotype, 1 male and 2 female paratypes (MRAC 180 112) from Pyrrhurus scandens (Swainson, 1837) (Pycnonotidae), Western Cameroon, V.1959, coll. unknown; 4 male paratypes and 5 female paratypes (MRAC 180 111 and 180 113), same data. Holotype and all paratypes MRAC.

Etymology: Specific epithet derives from the generic name of the host.

\section{Pteroherpus nicator sp. nov. (Figs 3A-D and 4D)}

Male (holotype): Idiosoma length $\times$ width $362 \times 215$ (idiosomal size in 6 paratypes $335-370 \times 195-223$ ). Length of hysterosoma 220. Prodorsal shield: Posterior angles rounded, lateral margins with narrow incision posterior to setae se, posterior margin convex, size $108 \times 92$, setae se separated by 80 . Setae $c 2$ hair-like, 35 in length; setae $c 3$ narrowly lanceolate, $45 \times 6$. Hysteronotal shield entire (Fig. 3A), not extending to level of setae $c 2$, anterior margin straight, anterior angles acute, length along midline 192, width at anterior margin 92. Distance between prodorsal and hysteronotal shields about 10. Opisthosomal lobes short, semi-ovate; margin of lobes with narrow membrane. Terminal cleft widely U-shaped, 12 long; length of the cleft including supranal concavity 38 . Setae $f 2$ situated ventrally. Dorsal measurements: $c 2: d 262, d 2: e 2$ 96, d2:gl 40, gl:e1 0-5, e2:h3 51, h2:h2 54, h3:h3 41. Transventral sclerite Y-shaped, 19 along midline, 20 in width in posterior part (Fig. 3B); tips of epiandrium extending to setae $4 a$; genital arch $28 \times 16$; aedeagus thin, as long as one third of genital arch. Adanal shield as small plate of irregular form (Fig. 3C). Diameter of anal discs 16. Ventral measurements: ps2:ps2 56, ps3:ps3 26, ps3:h3 46. Ventral membrane of tarsus I as long as $3 / 4$ of segment. Tarsus III 64 long, with narrow bidentate apex, all setae setiform, seta $w 32$, seta $s 14$, setae $r$ as long as segment (Fig. 3D). Tarsus IV subequal to tibia IV; modified seta $d$ in distal half of segment.

Female (paratype): Idiosoma length $\times$ width $440 \times 195$ (idiosomal size in 8 other paratypes $420-455 \times 180-210$ ). Length of hysterosoma 305. Prodorsal shield as in the male, $115 \times 95$, setae se separated by 83 . Setae $c 2$ short, hair-like, 25 long; setae $c 3$ narrowly lanceolate, $42 \times 5$. Arrangement of hysteronotal shields: Central sclerite, pair of lateral opisthosomal sclerites and pair of pygidial sclerites (Fig. 4D). Central sclerite as small longitudinal plate slightly enlarged posteriorly, not extending by posterior end to setae $e 1$, size $97 \times 45$. Lateral opisthosomal shields as longitudinal obliquely directed plates, with openings $g l$ in anterior part; 75-77 long, 26-28 wide. Setae $c l, c 2, d 1, d 2$ and $e 1$ on striated tegument, setae $e 2$ in anterior half of opisthosomal sclerites. Setae $p s 1$ at level of setae $h 2$. Dorsal measurements: $c 2: d 2$ 105, d2:e2 108, $d 2: g l$ 94, el:gl 10-12, e2:h3 95, h2:h2 94, h3:h3 68. Epigynium with lateral extensions and slightly divergent posterior ends, $45 \times 83$.

Diagnosis: The new species is close to Pteroherpus diploplax (Gaud et Mouchet, 1959) in having relatively small cen- 
tral sclerite in females and large region of striated tegument in sejugal area in both sexes. The males differ by shorter opisthosoma (lobar apices are at the level of the articulation femur/genu III) and shorter transventral sclerite, which is approximately as wide as long; the females differ by having the central sclerite narrowed in anterior part and not encompassing bases of setae $d l$ and by the absence of the inner opisthosomal sclerites. In the males of $P$. diploplax, the opisthosoma is elongated (lobar apices at level of the articulation genu/tibia III), and the transventral sclerite is 3 times as long

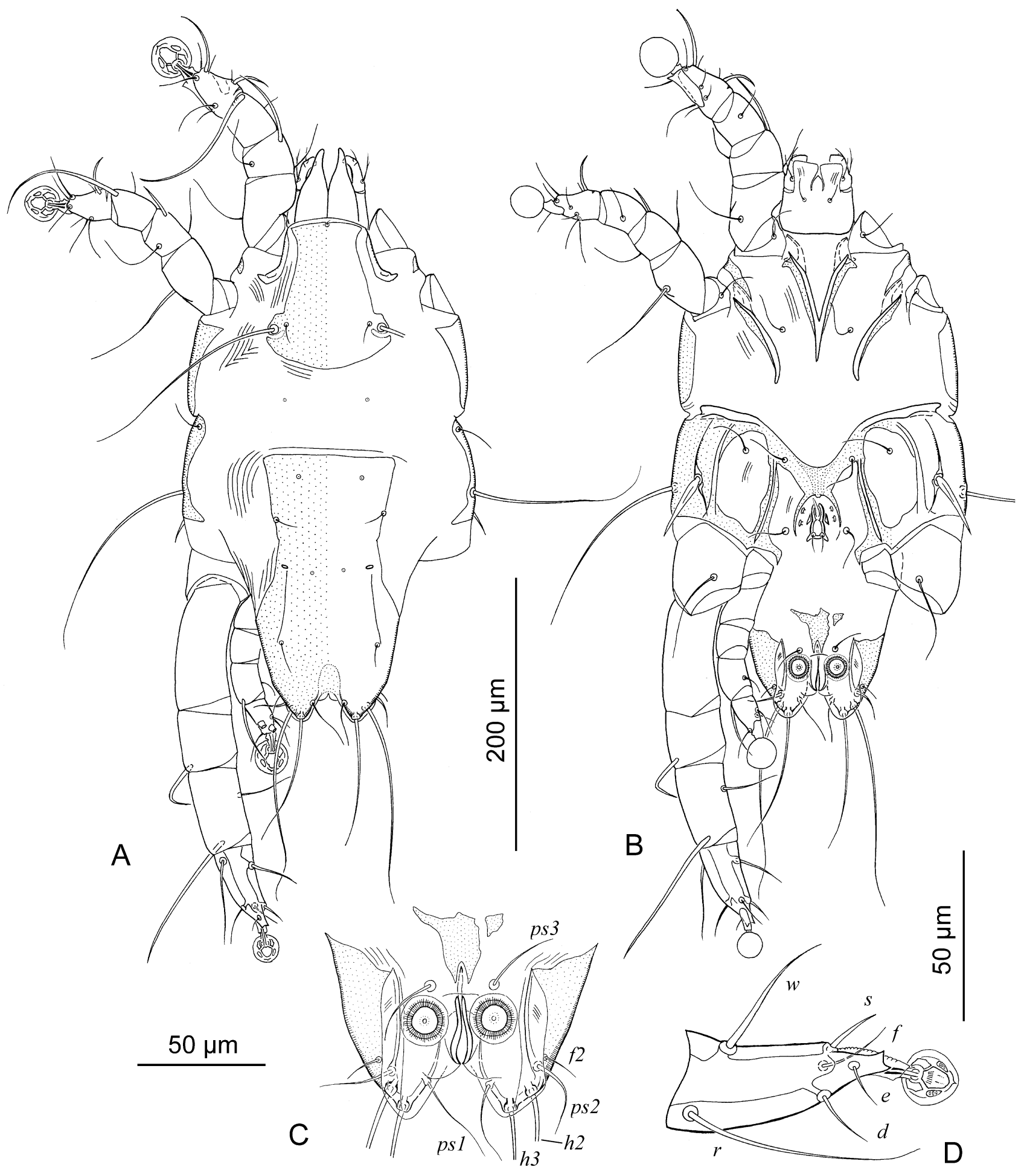

Fig. 3. Pteroherpus nicator sp. nov., male: A - dorsal view, B - ventral view, $\mathbf{C}$ - ventral view of opisthosoma, D - tarsus III, dorsal view 


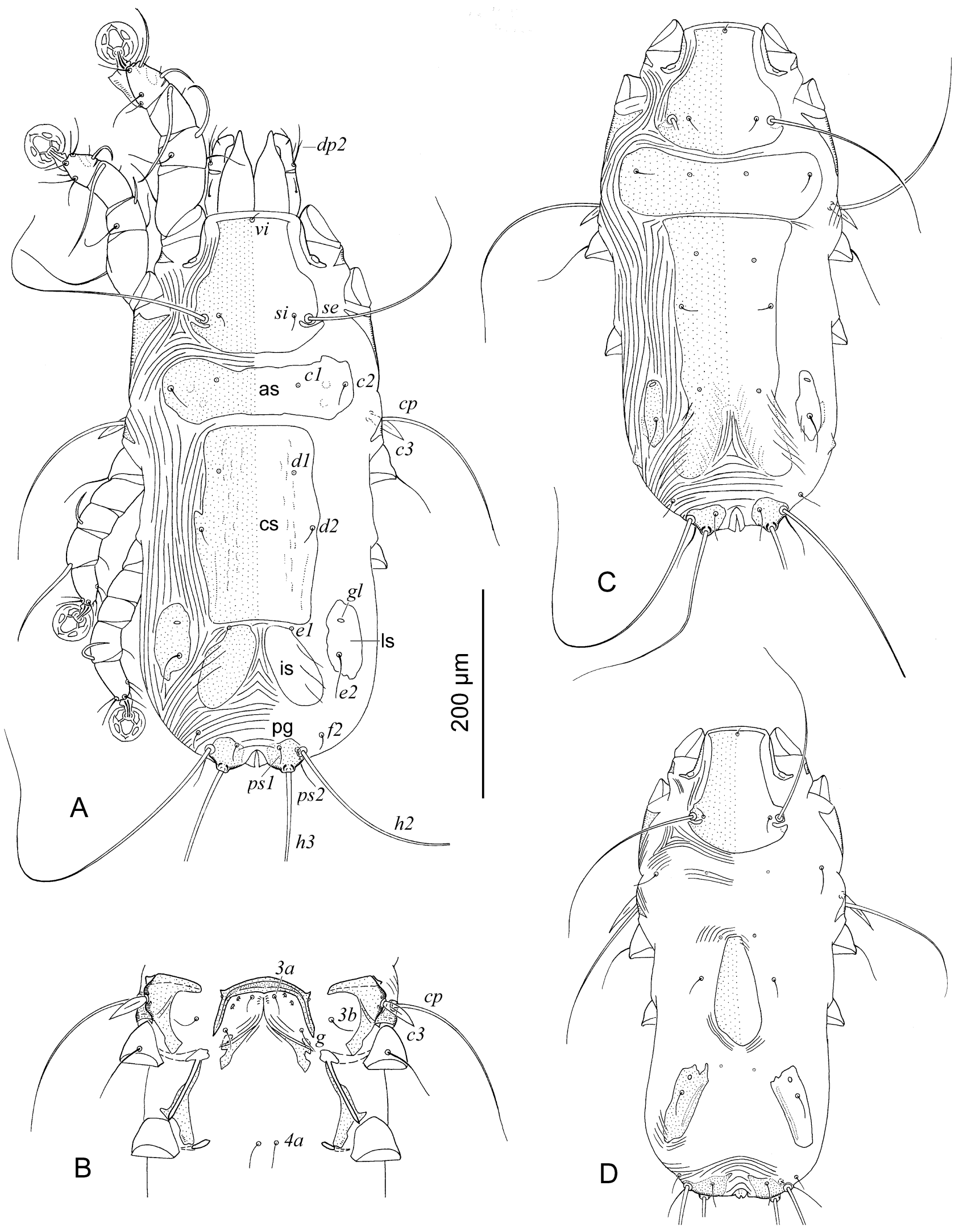

Fig. 4. Pteroherpus females: $\mathbf{A}-$ P. trinoton, dorsal view, $\mathbf{B}$ - same, ventral view of hysterosoma, $\mathbf{C}-$ P. pyrrhuri, dorsal view of idiosoma, D - P. nicator, dorsal view of idiosoma. Sclerites of hysteronotal shield: as - anterior hysteronotal sclerite, cs - central sclerite, is - inner opisthosomal sclerite, ls - lateral opisthosomal sclerite, pg - pygidial sclerite 
as wide; in the females, the central sclerite is generally rectangular and encompasses setae $d l$, and opisthosomal sclerites are represented by the lateral and inner fragments.

Type material: Male holotype and 1 male paratype (MRAC 180 125) from Nicator gularis Hartlaub et Finsch, 1870 (Pycnonotidae), South Africa, Zululand, Ndumu, 22.IX.1967, coll. unknown; 5 male paratypes and 12 female paratypes (MRAC 180 121-180 124, 180 126-180 130, 8 slides) with the same data. Holotype, 4 male and 10 female paratypes - MRAC, 2 male and 2 female paratypes - ZISP.

Etymology: Specific epithet is directly accepted from the generic name of the host and is a noun in apposition.

Acknowledgements. The authors thank Prof. W.T. Atyeo (The University of Georgia, Athens, U.S.A.) and Dr. H. André (Musée Royal de l'Afrique Centrale, Tervuren, Belgium) for loaning materials used in the present study, and Dr. H.C. Proctor (The University of Alberta, Edmonton, Canada) for critically reviewing the manuscript. This research is supported by a grant from the Belgian Scientific Policy to SVM.

\section{References}

Dickinson E.C. 2003. The Howard and Moore complete checklist of the birds of the world. Princeton University Press, Princeton, N.J.

Faccini J.L.H., Atyeo W.T. 1981. Generic revisions of the Pteronyssinae and Hyonyssinae (Analgoidea: Avenzoariidae). Proceedings of the Academy of Natural Sciences of Philadelphia, 133, 20-72.

Gaud J., Atyeo W.T. 1996. Feather mites of the world (Acarina, Astigmata): the supraspecific taxa. Musée Royal de l'Afrique Centrale, Annales, Sciences Zoologiques, 277, Part 1, 1-193 and Part 2, 1-436.
Gaud J., Mouchet J. 1959. Acariens plumicoles des oiseaux du Cameroun. V. Pterolichidae. Annales de Parasitologie Humaine et Comparée , 34, 493-545.

Mironov S.V. 1992. Five new species of the feather mite genus Pteroherpus Gaud (Analgoidea: Avenzoariidae) from passerine birds of Vietnam. International Journal of Acarology, 18, $1-12$.

Mironov S.V. 2001. Four new genera of the feather mite family Pteronyssidae Oudemans 1941 (Astigmata: Analgoidea) with notes on systematics of the family. Acarina, 9, 3-22.

Mironov S.V. 2003. A review of feather mites of the genus Neopteronyssus (Astigmata Pteronyssidae) associated with woodpeckers (Piciformes Picidae) of the Old World. Belgian Journal of Entomology, 5, 37-77.

Mironov S.V., Kopij G. 2000. New feather mite species of the family Pteronyssidae (Astigmata: Analgoidea) from South African passerines (Aves: Passeriformes). Folia Parasitologica, 47, 319-329.

Mironov S.V., Wauthy G. 2005a. A new feather mite species of the genus Hyonyssus Gaud and Mouchet, 1959 (Astigmata: Pteronyssidae) from the Tit-hylia Pholidornis rushiae (Passeriformes: Remizidae). International Journal of Acarology, 31, $101-106$

Mironov S.V., Wauthy G. 2005b. A new species of the feather mite genus Mouchetia Gaud, 1961 (Astigmata: Pteronyssidae) from the greencap eremomela Eremomela scotops (Passeriformes: Sylviidae) and taxonomic notes to species of the genus. Acarina, 13, 3-14.

Mironov S.V., Wauthy G. 2005c. A review of the feather mite genus Pteronyssoides Hull, 1931 (Astigmata: Pteronyssidae) from African and European passerines (Aves: Passeriformes) with analysis of mite phylogeny and host associations. Bulletin de l'Institut Royal des Sciences Naturelles de Belgique, Entomologie, 75, 155-214. 